\title{
Socio-economic differences in outdoor food advertising in a city in Northern England
}

\author{
Jean Adams*, Ellie Ganiti and Martin White \\ Institute of Health and Society, Newcastle University, Baddiley-Clark Building, Richardson Road, Newcastle upon \\ Tyne NE2 4AX, UK
}

Submitted 29 July 2010: Accepted 20 0ctober 2010: First published online 4 January 2011

\begin{abstract}
Objective: To explore differences in the prevalence of outdoor food advertising, and the type and nutritional content of advertised foods, according to an areabased marker of socio-economic position (SEP) in a city in Northern England.

Design: All outdoor advertisements in the city were identified during OctoberDecember 2009, their size (in $\mathrm{m}^{2}$ ) estimated and their location determined using a global positioning system device. Advertisements were classified as food or nonfood. Food advertisements were classified into one of six food categories. Information on the nutritional content of advertised foods was obtained from packaging and manufacturer's websites. An area-based marker of SEP was assigned using the location of each advertisement, grouped into three affluence tertiles for analysis.

Setting: A city in Northern England.

Subjects: None.

Results: In all, 1371 advertisements were identified; 211 (15\%) of these were for food. The advertisements covered $6765 \mathrm{~m}^{2}$, of which $1326 \mathrm{~m}^{2}$ (20\%) was for food. Total advertising and food advertising space was largest in the least affluent tertile. There was little evidence of socio-economic trends in the type or nutritional content of advertised foods.

Conclusions: Despite an absence of socio-economic differences in the type and nutritional content of advertised foods, there were socio-economic differences in food advertising space. There may also be socio-economic differences in exposure to outdoor food advertising.
\end{abstract}

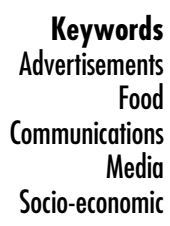

Obesity prevalence in England increased from $13 \%$ to $24 \%$ among men and from $16 \%$ to $25 \%$ among women between 1993 and $2007^{(1)}$. One important correlate of, and perhaps risk factor for, obesity is socio-economic position (SEP), with less affluent socio-economic groups experiencing higher levels of obesity ${ }^{(2)}$ and having greater consumption of foods high in energy density and low in micronutrients ${ }^{(3)}$.

Recently, attention has focused on environmental determinants of obesity and on the concept of the 'obesogenic environment $^{(4)}$. The relationship between environmental opportunities for healthy eating and physical activity and obesity prevalence has been well established by a number of studies ${ }^{(5)}$. Furthermore, there is some evidence that areas with a greater proportion of less affluent people appear to be more 'obesogenic', with fewer opportunities for healthy eating and physical activity than areas with a greater proportion of more affluent people ${ }^{(6)}$. However, these data are not entirely consistent with, for example, fast-food outlets showing concentration in more deprived neighbourhoods in some areas ${ }^{(7-9)}$, but not in others ${ }^{(10,11)}$.
One potentially important, but relatively unstudied, aspect of the obesogenic environment is outdoor food advertising. A recent systematic review concluded that food promotion has an influence on children's food preferences, purchasing requests and consumption ${ }^{(12)}$. Adults may also be vulnerable to the effects of food advertising $^{(13)}$. There are also potentially wider, indirect effects of food advertising in terms of normalising and increasing the salience of advertised products ${ }^{(14)}$.

The majority of previous work on food advertising has focused on television (TV) advertisements ${ }^{(15)}$ and, as awareness of the possible harms of food advertising has grown, calls for regulation have also increased $^{(16-19)}$. In the UK, scheduling restrictions on TV food advertising to children were introduced in 2007, prohibiting advertisements for less-healthy foods during and around programmes with a high proportion of child viewers ${ }^{(20)}$. However, outdoor food advertising in the UK is not subject to any particular content regulations ${ }^{(21)}$. 
Although we are unaware of any previous research on outdoor food advertising in the UK, research from other high-income countries shows some evidence of clustering of food and alcohol advertisements, particularly around schools and other institutions that tend to attract families ${ }^{(22,23)}$. The evidence on differences in advertising according to socio-economic characteristics is more mixed.

For example, advertisements for sugary beverages, fast food, alcohol and tobacco were found to cluster around child-serving institutions, particularly in neighbourhoods with high non-white populations, in Philadelphia (PA, USA) and Los Angeles (CA, USA) ${ }^{(22)}$. However, no evidence of any clustering was found in Austin (TX, USA), where regulations affecting outdoor advertising are stricter than in Philadelphia and Los Angeles.

In New Zealand, a pilot study found, contrary to expectation, that outdoor advertisements for foods inconsistent with government dietary recommendations were more prevalent in higher, compared with lower, income neighbourhoods. A study from Australia found a significantly higher prevalence of advertisements for foods that do not fit within government recommendations for a balanced diet within $500 \mathrm{~m}$ of a primary school, compared with other areas ${ }^{(24,25)}$.

These findings, in relation to outdoor food advertising, reflect those in relation to fast-food outlets discussed above. It seems likely that the clustering of aspects of the obesogenic environment, and the manner in which it does so, with factors such as deprivation varies from place to place ${ }^{(11)}$.

One possible reason for a higher prevalence of food advertisements in some areas, compared with others, within single cities is that marketers are targeting their campaigns at particular population groups. Alternatively, advertising sites in non-white areas, or around schools, may be cheaper and so preferred by marketers ${ }^{(26)}$.

Given the clear socio-economic differences in diet and obesity in the UK, the potential for outdoor advertising to affect these outcomes, and the international evidence that outdoor food advertisements can cluster in particular localities, we explored differences in total prevalence of outdoor food advertising, as well as the types and nutritional content of advertised foods, according to an area-level marker of SEP in one city in Northern England.

\section{Methods}

The study city, Newcastle upon Tyne, has a population of 259500 and is ranked as the thirty-seventh most deprived local authority area in England out of 354 such areas.

\section{Data collection}

We attempted to identify all outdoor advertisements, for any product, within the study city boundaries. Initial observations revealed that there were no outdoor advertisements in residential areas or on motorways. The study was, therefore, restricted to bus routes and areas around shops. All outdoor advertisements were identified by observation, photographed, their size in square metres estimated and their location determined using a handheld global positioning system device (Garmin eTrex; Garmin International Inc., Olathe, KS, USA). All data were collected by one researcher (E.G.) in October-December 2009.

\section{Food categories}

All advertisements were classified as food (including non-alcoholic drinks) or non-food (including alcoholic drinks). Food advertisements were further categorised into one of six groups on the basis of the five categories in the UK Food Standards Agency's 'Eatwell plate', plus an additional category: other foods.

\section{Nutritional information}

Information on the nutritional content of advertised foods was obtained from manufacturers' websites and packaging. This information was used to calculate the percentage of energy derived from protein, carbohydrate, sugar, fat and saturated fat, as well as the energy, fibre and $\mathrm{Na}$ density of all foods advertised. Nutritional information was also used to calculate whether advertised foods were considered 'high in fat, salt or sugar' (HFSS) according to the UK Food Standard Agency's Nutrient Profiling Model ${ }^{(27)}$. This model is used to identify 'less-healthy' foods that are subject to the UK TV food advertising scheduling restrictions ${ }^{(20)}$.

\section{Socio-economic position}

The SEP of the location of each food advertisement was measured using an area-based marker of deprivation called the English Index of Multiple Deprivation 2007 (IMD) ${ }^{(28)}$. This is determined from information on thirtyseven indicators within seven deprivation domains and can be calculated at various geographical levels. The smallest geographical level that IMD is available at is the lower super output area (LSOA). LSOA consists of small geographical areas containing around 1500 households. The LSOA of each advertisement was determined using grid references obtained from the handheld global positioning system unit. Using IMD gives an indication of the deprivation status of individuals living in close proximity to each advertisement and is used as a proxy of the SEP of these inanimate objects. IMD scores were then grouped into three tertiles for analysis - labelled as least affluent, middle and most affluent.

\section{Data analysis}

We took the size (in $\mathrm{m}^{2}$ ) of advertisements into account in the majority of our analyses, assuming that larger advertisements have a greater impact. 
Average nutritional content of advertised foods, weighted for the relative size of each advertisement, was described using medians and interquartile ranges, as distributions were non-normal. Data from the middle and most affluent tertiles were compared with data from the least affluent tertile using the Mann-Whitney $U$ test.

The distribution of food advertising space across food categories was calculated and the proportion of food advertising space that was, and was not, in each category in the middle and most affluent tertiles was compared with that in the least affluent tertile using Fisher's exact test. The same procedure was used to compare the proportion of food advertising space that was and was not for HFSS foods across tertiles.

\section{Results}

Table 1 shows the number and size of advertisements across IMD tertiles. A total of 1371 advertisements were identified, of which 211 (15\%) were for food. The proportion of advertisements that were for food was significantly smaller in the most $v$. the least affluent tertile, with some indication of a trend in the proportion of advertising space devoted to food decreasing as area affluence increased. Together, the advertisements identified covered an area of $6765 \mathrm{~m}^{2}$, of which $1326 \mathrm{~m}^{2}$ (20\%) was for food. The total advertising space and total food advertising space were substantially larger in the least affluent, compared with the middle and most affluent, tertiles. The proportion of all advertising space that was for food was significantly higher in the middle, compared with the least affluent, tertile, and lower in the most, compared with the least affluent, IMD tertile.

Table 2 shows the nutritional content of outdoor food advertisements, weighted by the relative size (in $\mathrm{m}^{2}$ ) of each advertisement. For comparison, the recommended ranges for avoidance of diet-related diseases provided by WHO and $\mathrm{FAO}^{(29)}$ are also shown. Compared with these recommendations, advertised foods tended to be high in fat and low in protein, carbohydrate and fibre.

There was little evidence that nutritional content showed any consistent trends across socio-economic tertiles. Statistically significant differences did suggest that foods advertised in the most affluent tertile were the poorest choice for health - being significantly higher in energy density $(P<0 \cdot 01)$, sugar $(P<0 \cdot 05)$ and fat $(P<0 \cdot 01)$ compared with foods advertised in the least affluent tertile. In contrast, foods advertised in the middle tertile appeared to be the best choice for health - being significantly lower in energy density $(P<0.01)$ and sugar $(P<0.001)$ compared with foods advertised in the least affluent tertile.

The most commonly advertised food in the sample was 'KFC Buffalo Toasted Twister' (thirty-one advertisements, $14.7 \%$ of food advertisements). This advertisement featured a close-up shot of the product with text describing the name, price and options for the product. All food advertisements featured a specific product or products,

Table 1 Number and size of outdoor advertisements (Newcastle upon Tyne, 2009)

\begin{tabular}{|c|c|c|c|c|c|c|c|c|}
\hline & & & \multicolumn{6}{|c|}{ Affluence tertile } \\
\hline & \multicolumn{2}{|c|}{ All } & \multicolumn{2}{|c|}{ Least affluent } & \multicolumn{2}{|c|}{ Middle } & \multicolumn{2}{|c|}{ Most affluent } \\
\hline & $n$ or $\mathrm{m}^{2}$ & $\%$ & $n$ or $\mathrm{m}^{2}$ & $\%$ & $n$ or $\mathrm{m}^{2}$ & $\%$ & $n$ or $\mathrm{m}^{2}$ & $\%$ \\
\hline All advertisements & 1371 & & 462 & & 432 & & 477 & \\
\hline $\begin{array}{l}\text { Food advertisements } \\
\text { Area of all advertisements }\left(\mathrm{m}^{2}\right)\end{array}$ & $\begin{array}{c}211 \\
6765 \cdot 2\end{array}$ & $15 \cdot 4$ & $\begin{array}{c}85 \\
3592.4\end{array}$ & $18 \cdot 4$ & $\begin{array}{c}64 \\
1467 \cdot 8\end{array}$ & $14 \cdot 8$ & $\begin{array}{c}62^{*} \\
1705 \cdot 0\end{array}$ & $13 \cdot c$ \\
\hline Area of food advertisements $\left(\mathrm{m}^{2}\right)$ & $1325 \cdot 8$ & $19 \cdot 6$ & $725 \cdot 0$ & $20 \cdot 2$ & $356 \cdot 0^{\star \star}$ & $24 \cdot 3$ & $244 \cdot 8^{\star \star *}$ & $14 \cdot 4$ \\
\hline
\end{tabular}

Values were significantly different from those of the least affluent tertile (Fisher's exact test): ${ }^{\star} P<0 \cdot 05,{ }^{\star \star} P<0 \cdot 01,{ }^{\star \star \star} P<0 \cdot 001$.

Table 2 Nutritional content of foods advertised, weighted for area $\left(\mathrm{m}^{2}\right)$ of advertisements (Newcastle upon Tyne, 2009)

\begin{tabular}{|c|c|c|c|c|c|c|c|c|c|}
\hline & \multirow[b]{3}{*}{ WHO/FAO range ${ }^{(29)}$} & \multirow{2}{*}{\multicolumn{2}{|c|}{ All }} & \multicolumn{6}{|c|}{ Affluence tertile } \\
\hline & & & & \multicolumn{2}{|c|}{ Least affluent } & \multicolumn{2}{|c|}{ Middle } & \multicolumn{2}{|c|}{ Most affluent } \\
\hline & & Median & IQR & Median & IQR & Median & IQR & Median & IQR \\
\hline Energy density (kJ/100 g) & - & 910 & $340-1228 \cdot 5$ & 910 & $231-1205 \cdot 5$ & $910^{* *}$ & $340-1144$ & $1092^{\star \star}$ & $472-2227$ \\
\hline$\%$ Energy from protein & $10-15$ & 6 & $0-21$ & 5 & $0-23$ & $12^{* *}$ & $0-21$ & 6 & $0-21$ \\
\hline \% Energy from carbohydrate & $55-75$ & 40 & $21-91$ & 41 & $19-91$ & $36^{*}$ & $31-57$ & 42 & $26-67$ \\
\hline$\%$ Energy from sugar & $<10$ & 9 & $2-87$ & 14 & $1-90$ & $9^{\star \star \star}$ & $1-27 \cdot 6$ & $40^{*}$ & $3-61$ \\
\hline$\%$ Energy from fat & $15-30$ & 41 & $0-52$ & 40 & $0-52$ & 44 & $0-48 \cdot 7$ & $44^{\star *}$ & $2-52$ \\
\hline$\%$ Energy from saturated fat & $<10$ & 9 & $0-27$ & 4 & $0-27$ & 9 & $0-24$ & 13 & $0-28$ \\
\hline Fibre density (g/MJ) & $>3 \cdot 0$ & 0 & $0-1$ & 0 & $0-1$ & $0^{\star \star \star}$ & $0-2$ & 0 & $0-1$ \\
\hline Na density (g/MJ) & $<0.2$ & 0 & $0-1$ & 0 & $0-0$ & $0^{\star \star \star}$ & $0-1$ & 0 & $0-0$ \\
\hline
\end{tabular}

IQR, interquartile range.

Values were significantly different from those of the least affluent tertile (Mann-Whitney $U$ test): ${ }^{\star} P<0 \cdot 05,{ }^{\star \star} P<0 \cdot 01,{ }^{\star \star \star} P<0 \cdot 001$. 


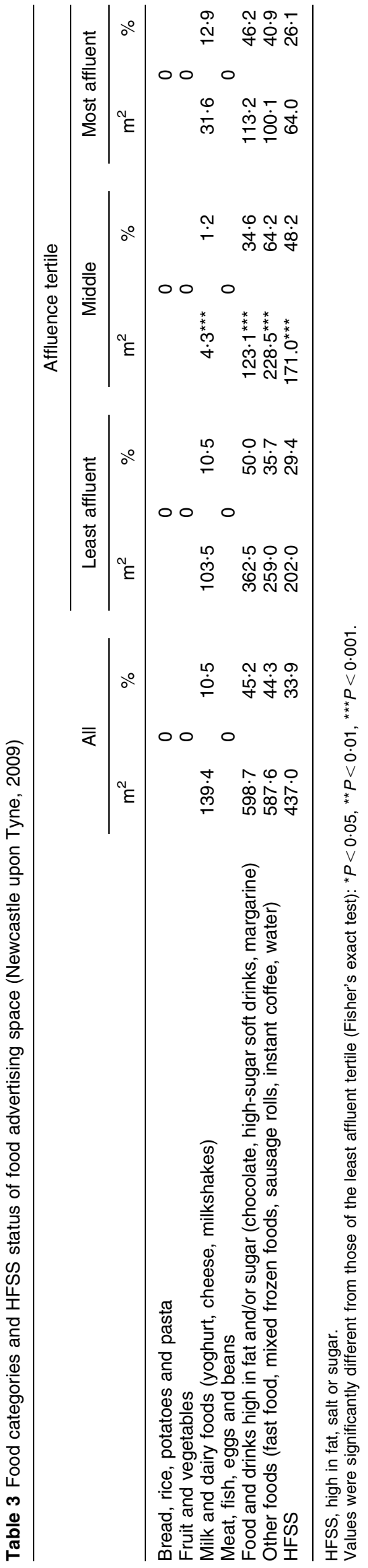

rather than being for wider brand ranges or restaurants in general.

The first six data rows of Table 3 show the food advertising space (in $\mathrm{m}^{2}$ ) devoted to each of the six food categories, overall as well as in each affluence tertile. Also shown are the main types of foods that were advertised within each food category. Only three of the six food categories were represented: 'milk and dairy foods', 'food and drinks high in fat and/or sugar' and 'other foods'. Significantly less advertising space was devoted to 'milk and dairy foods' and 'food and drinks high in fat and/or sugar' in the middle, compared with the least affluent, tertile $(P<0 \cdot 01)$. Significantly more advertising space was devoted to 'other foods' in the middle, compared with the least affluent, tertile $(P<0 \cdot 01)$. There was little evidence of consistent socio-economic trends across tertiles.

Just over one-third of food advertising space was devoted to HFSS products (last row, Table 3). The proportion of advertising space devoted to HFSS products was significantly higher in the middle than in the least affluent tertile $(P<0 \cdot 001)$.

\section{Discussion}

The present study is the first to examine outdoor food advertising in the UK and adds to the small international literature on socio-economic differences in outdoor food advertising.

We found that food accounted for $16 \%$ of all outdoor advertisements, but for $20 \%$ of all outdoor advertising space. Compared with a diet recommended for avoidance of diet-related diseases, advertised foods were noticeably high in fat and low in fibre, but within recommended ranges for sugar, saturated fat and $\mathrm{Na}$. Whereas almost half of food advertising space was devoted to 'food and drinks high in fat and/or sugar', only around one-third was devoted to foods that were HFSS and would be subject to scheduling restrictions on UK TV.

The absolute space, as well as the proportion of all advertising space, devoted to food advertising was lowest in the most affluent areas. There was little evidence of consistent trends in the nutritional content or type of food advertised according to an area-based marker of SEP. There was some indication that advertised foods had the least healthy nutritional profile in the most affluent areas.

To the best of our knowledge, ours is the first study to collect detailed nutritional information on foods advertised outdoors, rather than just classify foods into broad categories.

However, as data collection was performed by a single researcher (E.G.), it took more than a month to complete. It is likely that some advertisements changed during the data collection period and the data do not represent a true cross-section at one point in time. However, all advertising spaces were only viewed once and we avoided 
double counting of individual advertising spaces. In addition, many advertisements in the sample were for seasonal products related to the Christmas period (data were collected in October-December). It is likely that food advertising varies seasonally and our data may not be representative of outdoor food advertising at other times of the year. Further study is needed to explore seasonal variations in outdoor food advertising.

The small areas that IMD scores are calculated at are approximately equal in terms of population, but not necessarily of geographical area. This means that, although our IMD tertiles each represent approximately one-third of the population of the city, they do not necessarily represent similar geographical areas. We did not study advertising density and further studies should explore this.

By weighting our results according to size, we took into account one possible determinant of advertisement impact. However, there are likely to be other determinants of impact that we have not considered (e.g. location and creativity).

Furthermore, our data document what advertisements were present in Newcastle upon Tyne during the data collection period and where these were. This sample may not be representative of the UK more generally and, as discussed, the relationship between SEP and outdoor food advertising may vary substantially between different locales. Moreover, our data do not describe exposure to advertisements. It is not necessarily the case that an individual living near a particular advertisement is more exposed to it than someone living distant from it. Given our finding that outdoor advertisements were only present on bus routes or in shopping areas, exposure is also likely to occur during travel and shopping - both of which may take place geographically distant from where individuals live. Measuring exposure to advertisements was beyond the scope of the present study and should be explored in future research.

Almost half of food advertising space (45\%) was for 'food and drinks high in fat and/or sugar' that the UK government recommends should be eaten only 'sparingly'(30). In contrast, no advertisements were found for 'fruit and vegetables' that the UK government recommends consuming at least five portions per day ${ }^{(30)}$. Furthermore, more than one-third of food advertising space was devoted to HFSS products. Advertised foods were particularly high in fat and low in fibre. Overall, outdoor food advertisements, like food advertisements in magazines and on $\mathrm{TV}^{(24,30,31)}$, do not reflect current recommendations for healthy eating.

The total outdoor advertisement space (in $\mathrm{m}^{2}$ ), as well as that devoted to advertisements for food, was highest in the least affluent tertile and lowest in the most affluent tertile. This suggests that there is a higher availability of advertising space in less affluent areas and reflects similar findings from African-American neighbourhoods in New York city ${ }^{(26)}$. Kwate et $a l^{(32)}$ suggest that higher availability of advertising space in less affluent areas is due to a higher number of industrial estates and cheaper advertising rates. This may lead to socio-economic differences in exposure to outdoor food advertising.

We found some evidence that foods advertised in the most affluent areas were the poorest choice for health with the highest energy density and sugar and fat content. Although these results have some similarities to a previous study from New Zealand, where advertisements for "noncore' foods were more prevalent in higher-income neighbourhoods $^{(25)}$, they do not reflect known socio-economic differences in diet and obesity ${ }^{(3)}$ or previous data that have found clear socio-economic differences in food advertising in magazines ${ }^{(24)}$ and on $\mathrm{TV}^{(33)}$. This highlights that patterns of food advertising may not be similar across media.

We found very little variation in food advertising, with only forty-four food products represented in our total sample of 211 food advertisements. Few other published reports have included data on the number of individual products advertised, rather than the total number of advertisements found; hence, it is difficult to compare this finding with others. However, it may be that the outdoor sector is less varied and more repetitive than other advertising sectors. This may also explain the absence of socio-economic variations. Further research should explore this possibility.

\section{Conclusion and implications}

In the present study of outdoor food advertising in the UK, we found that outdoor food advertisements do not reflect current dietary recommendations. There was little evidence of socio-economic patterning in the type or nutritional content of foods advertised. However, the total absolute space devoted to food advertisements was highest in the least affluent areas and lowest in the most affluent areas and there may be socio-economic differences in exposure to outdoor food advertising. The determinants of obesity are complex and a holistic approach is required to understand and tackle obesity. However, there is now growing consensus that food promotion has a negative impact on children's food preferences and choices ${ }^{(12,13,34)}$. This has led to regulation of TV food advertising to children in the $\mathrm{UK}^{(20)}$. There is now emerging evidence that adults too are influenced by food advertisements ${ }^{(13)}$. By regulating food advertising in some spheres, but not in others, the UK government is sending very mixed messages to advertisers and consumers. A more consistent approach may be warranted with regulation of all food advertising, and not just TV food advertisements aimed at children. Local authorities in the UK and elsewhere may also want to consider using planning restrictions and other tools available to them to reduce outdoor food advertising.

\section{Acknowledgements}

J.A. and M.W. are members of Fuse - the Centre for Translational Research in Public Health that is funded 
by the British Heart Foundation, Cancer Research UK, Economic and Social Research Council, Medical Research Council and the National Institute for Health Research, under the auspices of the UK Clinical Research Collaboration. None of the authors have any conflict of interest to declare. J.A. and M.W. conceived the idea; E.G. collected the data; J.A. and E.G. performed the analysis and drafted the manuscript. All authors reviewed earlier drafts of the manuscript and have approved the final version.

\section{References}

1. Joint Health Services Unit (2008) Health Survey for England 2007: Latest Trends. London: NHS Information Centre.

2. Mutunga M, Gallagher AM, Boreham C et al. (2006) Socioeconomic differences in risk factors for obesity in adolescents in Northern Ireland. Int J Pediatr Obes 1, 114-119.

3. Darmon N \& Drewnowski A (2008) Does social class predict diet quality? Am J Clin Nutr 87, 1107-1117.

4. Egger G \& Swinburn B (1997) An 'ecological' approach to the obesity pandemic. BMJ 315, 477-480.

5. Schäfer Elinder L \& Jansson M (2009) Obesogenic environments? Aspects on measurement and indicators. Public Health Nutr 12, 307-315.

6. Macdonald L, Cummins S \& Macintyre S (2007) Neighbourhood fast food environment and area deprivation substitution or concentration? Appetite 49, 251-254.

7. Cummins SCJ, McKay L \& MacIntyre S (2005) McDonald's restaurants and neighborhood deprivation in Scotland and England. Am J Prev Med 29, 308-310.

8. Block JP, Scribner RA \& DeSalvo KB (2004) Fast food, race/ ethnicity, and income: a geographic analysis. Am J Prev Med 27, 211-217.

9. Pearce J, Blakely T, Witten K et al. (2007) Neighborhood deprivation and access to fast-food retailing: a national study. Am J Prev Med 32, 375-382.

10. Macintyre S, McKay L, Cummins S et al. (2005) Out-ofhome food outlets and area deprivation: case study in Glasgow, UK. Int J Behav Nutr Phys Act 2, 16.

11. Cummins S \& Macintyre S (2006) Food environments and obesity - neighbourhood or nation? Int J Epidemiol 35, 100-104.

12. Hastings G, McDermott L, Angus K et al. (2007) The Extent, Nature and Effects of Food Promotion to Children: A Review of the Evidence. Geneva: WHO.

13. Harris J, Bargh J \& Brownell K (2009) Priming effects of television food advertising on eating behavior. Health Psychol 28, 404-413.

14. Anon. (2003) The elephant in the room: evolution, behaviouralism, and counteradvertising in the coming war against obesity. Harv Law Rev 116, 1161-1184.

15. Hastings G, Stead M, McDermott L et al. (2003) Review of Research on the Effects of Food Promotion to Children, Final Report for the Food Standards Agency. Glasgow: Centre for Social Marketing.
16. Nestle M (2006) Food marketing and childhood obesity - a matter of policy. N Engl J Med 354, 2527-2529.

17. Halford J (2005) Serving up trouble? Advertising food to children. Psychologist 5, 284-287.

18. Department of Health (2004) Choosing Health: Making Healthy Choices Easier. London: HMSO.

19. Public Health Association of Australia Inc. (2006) Television Food Advertising During Children's Viewing Times - Position Statement. Deakin, ACT: Public Health Association of Australia Inc.

20. OfCom (2007) Television Advertising of Food and Drink Products to Children - Final Statement. London: OfCom.

21. Department for Communities and Local Government (2007) Outdoor Advertisements and Signs: A Guide for Advertisers. London: HMSO.

22. Hillier A, Cole BL, Smith TE et al. (2009) Clustering of unhealthy outdoor advertisements around child-serving institutions: a comparison of three cities. Health Place 15, 935-945.

23. Kelly B, Cretikos M, Rogers K et al. (2008) The commercial food landscape: outdoor food advertising around primary schools in Australia. Aust N Z J Public Health 32, 522-528.

24. Adams J \& White M (2009) Socio-economic and gender differences in nutritional content of foods advertised in popular UK weekly magazines. Eur J Public Health 19, 144-149.

25. Maher A, Wilson N \& Signal L (2005) Advertising and availability of 'obesogenic' foods around New Zealand secondary schools: a pilot study. $J N Z$ Med Assoc 118, 1.

26. Kwate NO \& Lee TH (2007) Ghettoizing outdoor advertising: disadvantage and ad panel density in black neighbourhoods. J Urban Health 84, 21-31.

27. Rayner M, Scarborough P, Boxer A et al. (2005) Nutrient Profiles: Development of Final Model. Final Report for the Food Standards Agency. Oxford: British Heart Foundation Health Promotion Research Group, Department of Public Health, University of Oxford.

28. Noble M, McLennan D, Wilkinson $\mathrm{K}$ et al. (2008) The English Indices of Deprivation 2007. London: Department of Communities and Local Government.

29. World Health Organization (2002) Diet, Nutrition and the Prevention of Chronic Diseases. Report of a Joint WHO/FAO Expert Consultation. WHO Technical Report Series no. 916. Geneva: WHO.

30. Food Standards Agency (2001) The Balance of Good Health. London: Food Standards Agency.

31. Adams J, Hennessy-Priest K, Ingimarsdóttir S et al. (2009) Changes in food advertisements during 'prime-time' television from 1991 to 2006 in the UK and Canada. Br J Nutr 102, 584-593.

32. Kwate NOA, Jernigan M \& Lee $T$ (2007) Prevalence, proximity and predictors of alcohol ads in Central Harlem. Alcohol Alcohol 42, 635-640.

33. Powell L, Szczypka G, Chaloupka F et al. (2007) Nutritional content of television food advertisements seen by children and adolescents in the United States. Pediatrics 120, 576-583.

34. McGinnis J, Goolman J \& Kraak V (2006) Food Marketing to Children and Youth: Threat or Opportunity? Washington, DC: The National Academies Press. 